Housing Studies

\title{
Discrimination and selection in the Belgian private rental market
}

\section{Kristof Heylen \& Katleen Van den Broeck}

To cite this article: Kristof Heylen \& Katleen Van den Broeck (2015): Discrimination and selection in the Belgian private rental market, Housing Studies, DOI:

10.1080/02673037.2015.1070798

To link to this article: http://dx.doi.org/10.1080/02673037.2015.1070798

曲 Published online: 27 Aug 2015.

4 Submit your article to this journal $\pi$

山 Article views: 11

Q View related articles ¿

View Crossmark data \lceil 


\title{
Discrimination and selection in the Belgian private rental market
}

\author{
Kristof Heylen and Katleen Van den Broeck \\ Research Institute for Work and Society (HIVA), University of Leuven (KUL), Leuven, Belgium
}

\begin{abstract}
In this paper, the results are presented of a study on discrimination and selection in the private rental market in Belgium. In contrast to other studies on the subject, we focus on different grounds of discrimination (ethnicity, disability, and gender) and selection (financial means). Two approaches in the field of behavioral experimental testing were used to measure the degree of discrimination/selection: a telephone and an email approach. In both approaches, a different experimental design was applied, with fictitious applicants for each discrimination ground and the control group. The fictional rental home seekers asked the landlord-by phone or e-mail-if the vacant dwelling was still available and if they could make an appointment for a visit. In the telephone approach, a sample of 684 online ads was used in a pairedtesting design, in which the landlords were contacted by both the control and experimental applicant. In the e-mail approach, a randomassignment design with a sample of 1769 online advertisements was used. The analyses revealed that discrimination for getting an appointment is found for each discrimination/selection ground in the email approach (only results for men), whereas people with Moroccan/Turkish names and disabled people were not found to be discriminated in the telephone approach. Furthermore, gender proved to be an important factor, as men with a Moroccan/Turkish background were discriminated in the phone-call approach (in contrast to women), whereas regarding financial means, women were treated more negatively than men.
\end{abstract}

\section{ARTICLE HISTORY}

Received 18 December 2014 Accepted 9 June 2015

\section{KEY WORDS}

Rental market; Belgium; discrimination; field experiment

\section{Introduction}

Discrimination based on one of the 'protected grounds' is illegal in Belgium. These protected criteria include-among others-ethnicity, gender, sexual orientation, disability, religion, marital status (source of) financial means, and disability. However, even if discrimination is illegal, the number of reports about discriminatory behavior increases yearly (Interfederal Centre for Equal Opportunities, 2014). The domains where discrimination is reported are mostly media and work, followed by access to goods and services including housing being more than one third of the reports in this domain. Reports about housing discrimination are 
usually related to the private rental market. In some of the city hotlines (where discrimination can be reported), discrimination on the housing rental market constituted nearly half of all discrimination reporting. Moreover, almost half of the reports in the housing domain are about the source of financial means, followed by racial discrimination and disability. Studies about discrimination in the housing market generally focus on only one of these grounds.

Given that housing is a constitutional right in Belgium and the importance of housing for social inclusion and the repeated calls from organizations operating in this area, the Interfederal Centre for Equal Opportunities commissioned a study called the housing diversity barometer'1 (Interfederal Centre for Equal Opportunities, 2014). The study included both the private rental and the public rental housing sector. Within the private rental sector part of the study, the whole search process from announcements of vacant dwellings to contacting the owner or real estate agency, visiting the dwelling, and eventually the content of the rental contract, was investigated by different quantitative and qualitative methods.

In this article, we present the results about discrimination in the contact phase of the private rental market in Belgium, where rental home seekers contact a (private) owner who put a vacancy announcement on a real estate website. Three discrimination and one selection ground were investigated, namely, those that according to the reports are most likely to experience discrimination in the housing market, the discrimination grounds are (1) ethnicity, (2) disability, and (3) gender combined with financial means (single mothers). In addition, the selection ground 'financial means, operationalized as reliance on social assistance or on occupational disability benefits, was investigated. In order to classify a tenant selection based on financial means as discrimination, the nature of the financial means (e.g. income for work, social assistance, or social insurance) should be the decision ground. In Belgian law, a different treatment according to the level of financial means is not regarded as discrimination, because it can be justified by a legitimate goal, which is the assessment of the ability to pay the rent. The design of our study allowed for measuring the impact of the (presumed) level of financial means, but not of the 'nature' of the means. With regard to the results according to financial means, we use the term 'negative treatment' instead of discrimination. Further, as some studies pointed at differences between male and female applicants (e.g. Ahmed \& Hammarstedt, 2008), we also included the gender aspect in our research design.

Our study focuses on discrimination and negative treatment in the Belgian private rental market. In Belgium, about 18 per cent of households occupied a private rented dwelling in 2009. Homeownership is the dominant tenure while the size of the social rented sector is relatively small. About 71 per cent of Belgian households own the dwelling they live in, while 7 per cent live in a social dwelling. Since the 1980s, housing policy has become a regional measure. Yet, the current regional policies (in Flanders, Wallonia and Brussels) have many common features. For instance, in each region a broad system of subject subsidies or extensive rental regulation is absent. Also, waiting lists and waiting time for social housing tend to be long. Therefore, vulnerable societal groups enter the private rental market, leading to a bigger affordability problem than in the other tenures (Heylen \& Haffner, 2013; Winters \& Heylen, 2014). In addition, policy instruments—such as housing subsidies-that affect the housing cost of private tenants are limited in scope (Heylen, 2013).

Since landlords are confronted with groups of vulnerable home-seekers, risk aversion may lead to strategies of selection and discrimination. Because landlords do not have perfect information about the future behavior of their tenants, a part of them may try to minimize 
the financial risk by-among others-using stereotypes about potential tenants. Landlords may treat different groups of applicants in a different way, because they believe that some observable features of candidates, such as ethnicity, are correlated with unobservable characteristics. They possibly believe that certain groups have a lower ability to pay, and include more risk. This type of discrimination is referred to as statistical discrimination. In addition, landlords may discriminate because of their own prejudice toward certain groups, and because they do not want to deal with them. If the non-selection of specified groups is merely based on a kind of aversion to these groups, the term 'taste-based discrimination' is used (Ahmed \& Hammarstedt, 2008; Yinger 1986).

Our study was conducted in 2013 , by using a multi-method approach. Two approaches in the field of behavioral experimental testing were applied to measure the degree of discrimination or selection: a telephone and an e-mail approach.

\section{Previous research}

The most studied ground of discrimination in the private rental market is the racial ground (Ahmed et al., 2010; Baldini \& Federici, 2011; Bosch et al., 2010; Carpusor \& Loges, 2006; Choi et al., 2005; Drydakis, 2011), which is sometimes combined with gender (Ahmed \& Hammarstedt, 2008; Bengtsson et al., 2012). Other examined discrimination grounds are (mental) disability (Centre for Equality Rights in Accommodation (CERA), 2009; Turner et al., 2005), sexual orientation (Ahmed et al., 2008; Lauster \& Easterbrook, 2011), household composition (Centre for Equality Rights in Accommodation (CERA), 2009; Galster \& Constantine, 1991; Lauster \& Easterbrook, 2011), and source of income (Centre for Equality Rights in Accommodation (CERA), 2009).

The countries or cities where these studies are typically conducted are situated in North America and Europe. In most of these studies, a certain degree of discrimination is discovered. In the studies on discrimination based on racial grounds in the United States, this can range from 4.5 per cent (Hanson \& Hawley, 2011) to 33 per cent (Carpusor \& Loges, 2006). In Europe, the level of discrimination for names of Arab origin compared to native origin varies from 15 per cent (for Spain; Bosch et al., 2010) to 25 per cent (for Stockholm; Ahmed \& Hammarstedt, 2008). In 2010, Bengtsson et al. (2012) found that females with Arabic names (compared to Swedish names) were discriminated, whereas the male group with Arab names was not discriminated. However, it is not straightforward to assume that differences in discrimination figures between cities or countries (from various studies) are based on real differences regarding discrimination between these cities or countries, because the effect depends on both the data collection method of the study and the definition of the discrimination rate.

Our hypothesis - based on the above-mentioned studies - is that discrimination in the Belgian private rental market exists for the grounds of ethnicity, disability, and financial means combined with gender (single mother). In addition, we expect a differential treatment of applicants according to their financial means. Given the range in discrimination rates in the different studies, it is difficult to specify expected figures for Belgium.

\section{The measurement of discrimination}

The technique of field experiments for measuring discrimination in the housing market has been in use for decades and is still frequently used. Until recently, the measurement of discrimination in the housing market was only done by personal approaches including a 
phone call or physical contact between the potential tenant and the landlord. These methods are called audits or situations tests (Heckman, 1998; Riach \& Rich, 2002). Here, fictitious candidate tenants (or buyers) are coupled or 'matched' in such a way that they are equal regarding the characteristics that are relevant for the landlord, but different with regard to the discrimination ground. The core of this method is to ensure that candidates are identical for relevant qualifications and characteristics, in order to exclude any intervening effects. The fictitious candidates are being trained in providing information as consistent as possible. The contact with the landlord is physically or by telephone. In the analysis, the discrimination ground is then causally related to differences in treatment between otherwise equal candidates. A general estimate of discrimination is produced by calculating the rate of differential treatment between the control and experimental group, in favor of the control group (Heckman, 1998). This treatment may relate to an appointment for visiting the vacant dwelling or to the communication that the dwelling is still available.

One possible problem with this method is that there are still variables that were not accounted for in the selection of a duo of potential tenants, such as the sound of the voice or the fluency of response, and possibly affect the outcome. It is believed by certain authors that, if the same pair of candidates contacts different landlords, the overall effect of these uncontrolled variables will be zero on average, but this assumption is quite strong (Heckman, 1998). Even though testers are thoroughly selected on relevant characteristics and trained to behave identically, it is impossible to be sure that their behavior during the contact with the landlord is identical. Moreover, the behavior of certain testers can for example be driven by the motivation to discover discrimination, consciously or unconsciously. These problems are seen as the weak spot of situation testing (Riach \& Rich, 2002). But by a lack of better alternatives, they are still frequently used and considered to produce credible evidence for the existence of discrimination.

Since there are a number of disadvantages associated with situation testing, and also because of the changing tools of communication, behavioral tests regarding the housing market are increasingly performed by emails. These are sent to people who offer a property for sale or rent. In the study by Carpusor and Loges (2006), in which the effect of namebased ethnic stereotypes is being tested, the email method was used for the first time. The problems mentioned above can thus be overcome by the use of e-mail-based testing during the first part of the selection process.

With regard to the email method, in general two types of designs are applied in research. Firstly, the 'matching' procedure is often used (e.g. in Ahmed \& Hammarstedt, 2008; Bosch et al., 2010; Hanson \& Hawley, 2011), where, as in situation testing, two (or more) profiles respond to an advertisement. The hints regarding age or income that are given in the email are identical, except for the discrimination grounds at stake. Second, a 'random assignment' procedure is used, in which only one e-mail is sent in response to a particular advertisement, either by the control or experimental group (e.g. Ahmed et al., 2010; Baldini \& Federici, 2011; Carpusor \& Loges, 2006). In this approach, each landlord will only be contacted once. Here, discrimination can be measured by the type of (or absence of) reply that is given. This can be an invitation for visiting, or a question for providing extra information. If a certain preference for a group exists, this will become clear by comparing the overall percentages for categories of replies (invitation, question for information, ...). Statistical significance tests will clarify whether these differences can be generalized to the population of advertisements (vacant dwellings). We opted for the random assignment approach, since the use 
of a matching procedure by email—and the receipt of two almost identical emails-may reveal the true nature of the study.

In the next section, the research design and some methodological issues will be discussed. In the third section, the results are presented. Finally, in the fourth section, conclusions are drawn.

\section{Multi-method experiment}

In our study, both the matching and random assignment approaches are used. They both have advantages and disadvantages, but we believe that a combination of both delivers a more comprehensive picture of discrimination at the point of contacting. We will focus on the discrimination with regard to getting appointments for a visit. The rate of discrimination is calculated as the difference between the percentages that receive an appointment between the control and experimental group.

With respect to the selection of tenants based on financial means, it is important to know that selection based on the level of income is not illegal in Belgium. In these cases, we do not talk about discrimination but about selection. Only when landlords decide not to consider home seekers based on the source of the income (e.g. unemployment benefit), disregarding their income level, this is not legal and should be called discrimination. For instance, if a landlord turns down candidates with unemployment benefits because he perceives them as lazy and undeserving of a decent dwelling, this is a form of discrimination. In order to test discrimination based on the source of income, a different experimental design is needed than the one applied in our study, in which the source of income is the only variable that is different between the control and experimental group. In our study, not only the source of income but also the level was different between the control (median income) and experimental group (benefits are lower than median income). Therefore, when we discuss our results for differences according to financial means, we speak of selection (rates) instead of discrimination (rates).

\section{Research design for telephone approach}

We used a random sample of recent advertisements for rental dwellings in each region of Belgium, in both parts of the study. We only included advertisements posted by private landlords. We consider the rental market segment managed by landlords separate from the segment managed by commercial real estate agencies. Possible differences between both segments are e.g. the frequency with which they have to find tenants and the screening procedures/selection criteria they use. The market presence of real estate agencies also differs by region. In Flanders, 38 per cent of private rental dwellings are managed by real estate agencies (Heylen, 2015), whereas this figure is significantly lower in Wallonia. Beforehand it is difficult to predict whether dwellings managed by real estate agencies will include more or less discrimination than dwellings managed by individuals. While one segment (dwellings managed by real estate agencies) is more formalized and controlled (allowing less opportunities to discriminate), the other segment allows more individual and personal contact between landlord and tenant which may be in the advantage of the tenant (offering more opportunities for an individual candidate to eliminate statistical discrimination). In any case, our results only hold for the segment of private landlords.

In the first part, using a telephone approach and a matching process, every landlord was contacted by a pair of testers. Although recent studies have mostly opted for the approach 
by email, calling by phone still involves certain advantages. First, also ads that only include a telephone number (and no email address) can be contacted. In addition, a telephone approach better reflects the reality of the rental market in Brussels, where tenants need to react fast to ads in order to find a suitable rental house. In this respect, sending an email is not the fastest way to contact a landlord. Furthermore, the email approach implies the risk that many emails will not be answered by the landlords (low response).

Between February and April 2013, 684 tests were conducted by telephone (meaning 1368 calls), more or less evenly divided between the three Belgian regions and the four grounds of discrimination. This sample of ads was based on a screening of ads on the popular real estate websites 'Immoweb' and 'Vlan', taking into account regional differences and differences between large and small urban areas. The selection was made in 133 municipalities. Moreover, an upper limit for rent was applied. More specifically, only rents below the 90th percentile of the rent distribution in the private market were taken into account (based on rent data in EU-SILC 2009, indexed to 2013). For Flanders, the maximum rent was set at 759 euro/month, whereas for Wallonia and the Brussels Capital Regions, it was, respectively, set at 711 and 867 euro/month.

With regard to selection ground 'financial means,' given the socioeconomic weak profile of the fictitious tenant, the maximum rent was set lower, at a level to $500 €$ in the three regions. As a result, the discrimination and selection figures in this paper only refer to this part of the housing market. Also, we assured an approximately equal distribution of male and female testers. The callers had to follow a standard question process, but were also prepared for additional questions from the landlord. In order to make the call in a natural and smooth way, the callers were handed standard profiles, relating to their (fictitious) occupation, income, or family composition. The period between the contact moments of the control caller and the experimental caller was maximum two hours, and all calls were conducted between 16 and $20 \mathrm{~h}$. In half of the cases, the first call was done by the control group, while in the other half the experimental group called the first.

The control group was represented by a fictitious tenant with a typical Belgian sounding name (French or Dutch according to the region). A first experimental group was represented by a fictitious home-seeker with a name that signals a Turkish or Moroccan origin (ethnic ground). The experimental testers representing the rental home-seekers with Turkish or Moroccan background spoke the local official language (French or Dutch) fluently. The choice for people with a Turkish and Moroccan background was made because they are the largest non-EU immigrant groups in Belgium ${ }^{2}$. A second fictional tenant is a blind person (with Belgian name) (disability discrimination ground). In both the phone call and email approach, this fictitious disabled prospective tenant asks whether it is possible to describe the dwelling in detail. A third experimental group was represented by a single mother with a child of about one year old (a combination of discrimination grounds gender and means). A final fictitious tenant is a person entitled to social assistance or a disability benefit (discrimination based on financial means). The control group was always of the same sex as the experimental group except in the case of the combined ground of gender and means, where the control group consists of men and the experimental group of women.

The callers (fictitious prospective tenants) completed a standard form immediately after the call, with the following aspects: the availability of the house (yes/no), question for further information (yes/no), type of information, and invitation to visit the house (yes/ no). In this study the 'invitation for a visit' will be analyzed, since we regard it as the most 
crucial outcome. In order to provide as little inconvenience as possible for the landlord, the appointment (if made) was canceled shortly afterwards, with the excuse that another dwelling was found.

Because there are always two test persons calling the same landlord, there are always four possible outcomes: (1) the two candidates, both the control and experimental caller, were denied a visit, (2) both candidates received a positive response (both managed to arrange a visit), (3) the control group received a positive response and the experimental group received a negative response, and (4) the experimental group received a positive answer and the control group a negative. The (net) discrimination level can be calculated as the ratio of the difference between the number of cases where the experimental group is treated disadvantageously and the number of cases where the control group got a disadvantageous treatment, to either (1) the total number of observations or (2) the number of cases in which at least one of the callers received a positive response. The choice of denominator depends on whether one considers situations in which both groups received a negative response as an equal treatment (1) or as a non-observation (2). We follow Riach \& Rich (2002) in their defense of the latter (both negative answer = non-observation) for situations where the landlord actually was not faced with the opportunity to make a discriminating choice. For instance, when the property was already rented (in both cases).

In addition to the discussed bivariate calculation of the degree of discrimination, we calculated the degree of discrimination also by regression analysis. This way, we could measure discrimination, controlling for the potential intervening impact of some relevant dwelling characteristics, such as the number of rooms, the dwelling size, the region, and the rent level. For example, if a specific profile had systematically more calls for small dwellings, and if there is more opportunity for discriminatory behavior in the more tight market for small houses, this may lead to a biased (higher) level of discrimination.

The multivariate analysis is performed by using a probit regression in which the included explanatory variables (experimental/control group, region of the dwelling (Flanders, Wallonia, Brussels Capital Region), the price and number of rooms) determine the likelihood that a prospective tenant gets an appointment or not. The figure that we focus on (and refer to as level or rate of discrimination) is the estimated probability (for a visit) for the experimental group compared to the control group. Thus, the level of discrimination shows to what extent the probability for receiving an appointment is higher $(+)$ or lower $(-)$ for the experimental compared to the control group. In the telephone approach, we do not expect the bivariate and multivariate results to differ much since the differences are captured by the design (the matched pairs call the same landlord, which entails that the characteristics of the dwelling are the same).

\section{Research design for email approach}

In the second part, by applying a random assignment method, each landlord (from the sample of ads) was contacted by email only once. The emails were kept as identical as possible, except for the necessary variation in terms of discrimination grounds. This email approach involves a risk of getting a poor response rate. However, international studies-there are still no internet studies for Belgium-show that more than 50 per cent of the emails were replied by the landlord.

In the email approach, we worked out five fictitious profiles (or standards emails): one for the control group and four for the different experimental groups, similar to the profiles 
which were used in the telephone approach. Unlike the telephone approach, in the email approach only male prospective tenants are used (except in the experimental profile of the single mothers). The sex of the control group had to be male, because one of the four experimental profiles, the single mother, has to be compared with a male control group in order to capture the gender dimension. Since the (only) control group is male, the other three experimental profiles had to be male too. The differences by ethnicity (Turkish/Moroccan) and type of income (social assistance/disability benefit) are evaluated the same way as in the telephone approach (signature and email address with foreign sounding name). An email address was created using gmail, hotmail, and other providers, while the emails were sent via the link that was provided in the advertisements. In each of the three regions, a sample was used of about 590 recent ads for rental dwellings, drawn from the same websites (Immoweb, Vlan) and 133 municipalities as in the telephone approach. About 23 per cent of Belgian municipalities were represented in the sample, which was based on socio-geographical strata. The five profiles were randomly assigned to the ads so that every landlord received an email of only one of the five profiles.

In the email, the group with lower financial means gives the necessary information by referring to their situation and trying to reassure the landlord that their means are sufficient. This is not only done for the source, but also for the level of income (social assistance of $800 €$ and disability benefit of $1200 €$ ). The 1769 emails were sent between April and May 2013. The responses to the emails were monitored and coded up to two weeks after sending the email. In order to bother the landlord as little as possible, a standard email was sent in case the landlord answered the initial mail, with a polite notice that there was no more interest in the dwelling. Our analysis will focus on the invitation to a visit (yes/no). Also in the email part, the results are calculated in a bivariate and multivariate way. In the telephone approach, we do not expect much difference between the bivariate and multivariate results, due to the paired design. In the mail approach on the other hand approach, where each landlord is only contacted by one email, there may be a greater discrepancy.

\section{Type of discrimination}

As mentioned, there is a difference between taste-based and statistical discrimination. In this study, we estimate the rate of discrimination, while not distinguishing between the two types of discrimination. What we measure is in fact a combination of both. Part of the discrimination arises from a kind of aversion against a particular group, regardless of the average relevant characteristics of this group with regard to renting (taste-based discrimination). Another part of the discrimination is due to prejudices of landlords toward a certain type of potential tenants because they ascribe certain characteristics to the group to which the candidate belongs, such as a lower ability to pay or maintain their homes (statistical discrimination). This type of discrimination can only be revealed in a testing design where the only (relevant) factor that varies between experimental and control group is the studied discrimination ground.

We do not rule out statistical discrimination in the telephone approach since we did not train the callers in such a way that they always mentioned their income or occupation. These background features were only mentioned if the landlord asked for it. Also in the email approach the income was not mentioned, except for the profiles of low financial means (the levels of social assistance and disability benefit was mentioned). A part of the discrimination that was found with regard to ethnicity is therefore likely to be statistical 
Table 1. Bivariate discrimination levels for getting an appointment, landlords in the private rental market, Belgium.

\begin{tabular}{lccccc}
\hline & \multicolumn{3}{c}{ Telephone } & & Email \\
\cline { 2 - 3 } & Total & Women & Men & & Men \\
\hline Ethnicity & 5.4 & -3.4 & $13.7^{* * *}$ & & $18.6^{* * * *}$ \\
Single mother & $5.1^{* *}$ & $5.1^{* *}$ & - & $-3^{*}$ & \\
Disability & 5.1 & 1.2 & $12.3^{* * * *}$ \\
Financial means & $13.5^{* * *}$ & $16.9^{* * *}$ & 9.9 & & $24.5^{* * *}$ \\
\hline
\end{tabular}

Note: A negative sign implies a reverse discrimination (control group being disadvantaged).

${ }^{a}$ For the discrimination ground 'single mother' the experimental profile is female.

${ }^{*} p<0.10$; ${ }^{* *} p<0.05 ;{ }^{* * *} p<0.01$, McNemar test.

discrimination, meaning that this group in general is seen as a group with a lower ability to pay. Statistical discrimination could be reduced by providing more information. But then, it becomes difficult to present the profiles in a 'smooth' and credible way, as callers would have to mention their income level (and maybe even occupation) in each phonecall and emails would also have to include this information in a standard way. Taking this into consideration, the discrimination levels in our study can be considered upper limits for taste-based discrimination.

\section{Results}

\section{Descriptive statistics for level of discrimination}

Table 1 shows the results according to the calculation of the discrimination level in a descriptive way, as discussed in the methodological section. These results are not controlled for the possible intervening impact of contextual variables such as number of rooms, rental price, or region. We focus on the differences in getting an appointment to visit the dwelling. The table shows that the discrimination level is higher in the email than in the telephone approach. In one out of four times, people with low financial means are treated negatively by email, whereas this figure is 13 per cent when landlords are contacted by phone. Regarding ethnicity, in the phone-call method only men are discriminated. Their probability of getting an appointment is 13.7 per cent point lower than for the control group. In the email approach, this level rises to 18.6 per cent. With regard to single mothers, the discrimination rate is rather moderate in the telephone approach (5.1 per cent) and slightly higher in case emails were sent ( 7.3 per cent). Finally, disabled men are discriminated in 9 out of 100 times by phone whereas this rate is remarkably higher (12.5) by email. Possibly, landlords feel more comfortable when they can discriminate/select by email than by phone, where a direct contact takes place with the person.

The next section shows the results according to the probit regression analyses. As pointed out before, we only expect major differences in outcome for the email approach since there was no matching of control and experimental group. In the telephone approach, the paired testers addressed the same ad, entailing that dwelling characteristics cannot vary. Since the results of the regression analyses are more accurate, the overall conclusions will be based on them.

\section{Estimates for probability of getting an appointment}

Table 2 shows the results of the multivariate analysis for the ethnic discrimination ground, with regard to getting an appointment for a visit. The numbers included are marginal effects 
Table 2. Probability of getting an appointment, for people with a foreign ethnic background, marginal effects.

\begin{tabular}{lccccc}
\hline & \multicolumn{3}{c}{ Telephone $^{\mathrm{a}}$} & & Email $^{\mathrm{b}}$ \\
\cline { 2 - 4 } & Total (1) & Men (2) & Women (3) & Men (4) \\
\hline Ethnic ground vs. control group & -0.054 & $-0.138^{* *}$ & 0.022 & & $-0.127^{* * *}$ \\
$N$ & 377 & 193 & 184 & 707 \\
\hline
\end{tabular}

a Marginal effects based on probit regression, with clustering on the level of landlord.

${ }^{b}$ Marginal effects based on robust probit regressions. Coefficients of control variables (number of rooms, region, rent) not presented.

${ }^{* * *} p<0.01 ;{ }^{* *} p<0.05$

Table 3. Probability of getting an appointment, for single mothers, marginal effects.

\begin{tabular}{lcc}
\hline & Telephone $^{\text {a }}$ & Email $^{\mathrm{b}}$ \\
\hline Single mother vs. male control group & $-0.055^{* *}$ & $-0.061^{*}$ \\
$N$ & 353 & 690 \\
\hline
\end{tabular}

Note: Coefficients of control variables not presented.

a Marginal effects based on probit regression, with clustering on the level of landlord.

${ }^{b}$ Marginal effects based on robust probit regressions.

${ }^{* *} p<0.05 ;{ }^{*} p<0.1$.

Table 4. Probability of getting an appointment, for people with a disability, marginal effects.

\begin{tabular}{lccccc}
\hline & \multicolumn{3}{c}{ Telephone $^{\mathrm{a}}$} & & Email $^{\mathrm{b}}$ \\
\cline { 2 - 4 } \cline { 2 - 3 } & Total (1) & Men (2) & Women (3) & & Men (4) \\
\hline Blind person vs. control group & -0.049 & -0.080 & -0.022 & $-0.072^{* *}$ \\
$N$ & 364 & 187 & 177 & 653
\end{tabular}

Note: Coefficients of control variables (number of rooms, region, rent) not presented. a Marginal effects based on probit regression, with clustering on the level of landlord.

${ }^{b}$ Marginal effects based on robust probit regressions.

${ }^{* *} p<0.05$.

Table 5. Probability of getting an appointment, for people with low financial means, marginal effects.

\begin{tabular}{|c|c|c|c|c|}
\hline & \multicolumn{3}{|c|}{ Telephone ${ }^{a}$} & \multirow{2}{*}{$\frac{\text { Email }^{\mathrm{b}}}{\text { Men (4) }}$} \\
\hline & Total (1) & Men (2) & Women (3) & \\
\hline $\begin{array}{l}\text { Means caller/mailer vs. control group } \\
N\end{array}$ & $\begin{array}{c}-0.124^{* *} \\
282\end{array}$ & $\begin{array}{l}-0.082 \\
134\end{array}$ & $\begin{array}{c}-0.170^{* *} \\
148\end{array}$ & $\begin{array}{l}-0.135^{* * *} \\
719\end{array}$ \\
\hline
\end{tabular}

Note: Coefficients of control variables (number of rooms, region, and rent) not presented.

aMarginal effects based on probit regression, with clustering on the level of landlord.

${ }^{b}$ Marginal effects based on robust probit regressions.

${ }^{* * *} p<0.01 ; * * 0<0.05$.

calculated from a probit regression model. These can be interpreted as follows: the numbers give the change in the probability of getting an invitation when the caller changes from being control group to the ethnic experimental group, all other variables being equal. The coefficient in column 1 shows that the probability of getting an invitation would decrease by five percent (if it was significant) if, all other factors equal, the caller would change from being control group to experimental group. This measure is an estimate of the level of discrimination against callers with a Turkish or Moroccan name. In total, we do not find a significant result. However, when the male and female subsamples are analyzed separately 
Table 6. Overview of discrimination (and selection) levels for getting an appointment, landlords in the private rental sector, Belgium.

\begin{tabular}{|c|c|c|c|c|c|c|c|c|}
\hline & \multicolumn{6}{|c|}{ Telephone approach } & \multirow{2}{*}{\multicolumn{2}{|c|}{$\frac{\text { Email approach }}{\text { Men }^{\mathrm{a}}}$}} \\
\hline & \multicolumn{2}{|c|}{ Total } & \multicolumn{2}{|c|}{ Women } & \multicolumn{2}{|c|}{ Men } & & \\
\hline & Bivariate & Multivariate & Bivariate & $\begin{array}{l}\text { Multi- } \\
\text { variate }\end{array}$ & Bivariate & $\begin{array}{l}\text { Multi- } \\
\text { variate }\end{array}$ & Bivariate & Multivariate \\
\hline Ethnicity & 5.4 & 5.4 & -3.4 & -2.2 & $13.7^{* * *}$ & $13.8^{* *}$ & $18.6^{* * *}$ & $12.7^{* * *}$ \\
\hline $\begin{array}{l}\text { Single } \\
\text { mother }\end{array}$ & $5.1^{* *}$ & $5.5^{* *}$ & $5.1^{* *}$ & $5.5^{* *}$ & & & $7.3^{* *}$ & $6.1^{*}$ \\
\hline Disability & 5.1 & -4.9 & 1.2 & 2.2 & $8.7^{*}$ & 8.0 & $12.5^{* * *}$ & $7.2^{* *}$ \\
\hline $\begin{array}{l}\text { Financial } \\
\text { means }\end{array}$ & $13.5^{* * *}$ & $12.4^{* *}$ & $16.9^{* * *}$ & $17.0^{* *}$ & 9.9 & 8.2 & $24.5^{* * *}$ & $13.5^{* * *}$ \\
\hline
\end{tabular}

a'For the 'single mother' the experimental profile is female; a negative sign implies a reverse discrimination (control group being disadvantaged).

${ }^{*} p<0.10 ;{ }^{* *} p<0.05 ;{ }^{* * *} p<0.01$.

(column 2), the probability of getting an invitation to visit the dwelling is about 14 per cent point lower for the Turkish/Moroccan men than for the control group (men with typically Belgian sounding names). The result of the email approach was similar with a discrimination percentage of 13 .

This seems to be on the lower end of what is found in studies in other European countries (see 'previous research').

In Table 3, the results are presented for the single mother as experimental group. We found that single mothers, compared to the male control group, have a probability of being discriminated which is 5.5 per cent point higher when contact is made by telephone, and 6.1 per cent point higher when an email was sent. Thus, both results are quite equal. It is clear that these discrimination rates are significant, but we need to be careful in interpreting this result, and keep in mind that the control group is a man without a child. Discrimination can be caused by gender (since the control group is male), the presumption of low financial means (being single parent), or the family situation (having a young child). Lauster and Easterbrook's (2011) results suggested that discrimination against single parents was primarily based on their economic marginalization rather than on other forms of prejudice. They found discrimination rates against single mothers of around 15 per cent (response rates compared to a heterosexual couple) for metropolitan Vancouver.

With regard to people with a disability_operationalized as blind people-no significant discrimination rate was found in the telephone approach (Table 4). Also, when the results are considered for male and female separately, no effect was present. However, in case an email was sent (by a male), the likelihood of getting an appointment was significantly lower (7.2 per cent point) than for the male control group.

In line with the descriptive analysis on this topic, these results suggest that blind people should rather rely on a telephone contact than on sending an email, to enhance their chances of finding a dwelling. It is possible that the threshold for discriminating blind people on the phone is higher than by email. Another possible explanation is that providing information about the dwelling, which was asked by the fictitious blind home seekers in both our approaches, is easier on the phone than in an email.

Finally, the results of selection according to financial means is presented in Table 5. We found an overall significant selection rate of 12.4 per cent. Split by gender, women have a probability of being invited for a visit which is 17 per cent point lower than the (female) 
control group. In contrast, the figure for men is not statistically significant in the phonecall approach. However, in the email approach, men with lower financial means are being treated negatively in 13.5 per cent of cases. In addition, in the email approach, selection by landlords depends on the type of replacement income. People receiving a disability benefit were found to be negatively treated in 10.5 per cent of cases, whereas this figure is 15.8 per cent for people on social assistance (figures not in table, but see Van den Broeck \& Heylen, 2014).

Table 6 presents an overview of the results of the descriptive (bivariate) and the probit regression analyses, with the probability of getting an appointment as dependent variable. This table clearly shows that the regression analysis produces different results than the bivariate analysis in the email approach. More specifically, it lowers the level of discrimination to a considerable extent, except for disabled people, where the decrease is small. In the phone-call approach, as expected, differences between the analyses types are minor.

\section{Conclusion}

Our study focused on an issue that has reached the societal agenda in Belgium in recent years: the discrimination and negative treatment of rental homeseekers by private landlords. For instance, the number of reports about discriminatory behavior-in different domains-is increasing year by year (Interfederal Centre for Equal Opportunities, 2014). Since landlords can be reached by telephone or-increasingly in recent years-email, two approaches were applied in an experimental design. Yet, in the email approach only male groups were analyzed, whereas the telephone approach allowed for a comparison between the treatment of male and female applicants.

The results, based on a multi-method field experiment, confirmed our hypotheses that discrimination based on ethnicity, disability (blind person), and gender combined with financial means (lone mother), and selection based on financial means, is present in the Belgian private rental market. But discrimination did not take place for each experimental group for each ground. Furthermore, the rate of discrimination (selection) strongly differs between the grounds of discrimination (selection). We found that, both in the telephone and email approach, people with low financial means face the highest levels of selection. In more or less 13 per cent of cases, they were treated negatively compared to the control group. Further, people with Moroccan/Turkish names-but fluently expressing themselves in Dutch or French-are discriminated in the email approach (only men) but not in the telephone approach. However, analyzed separately, men with Moroccan/Turkish names are discriminated in about 13 per cent of times in the telephone approach, whereas women from this group are not discriminated by phone. Single mothers are discriminated to a relatively small extent, both by telephone and email. Finally, blind people were only significantly discriminated in the email approach (only men), but to a limited extent (7.2 per cent).

The high rate of selection for people with a replacement income presumably signals a shortage of rental dwellings in the market segment of low-cost (with low returns on investment) or social dwellings (indicated by long waiting lists). A high number of home seekers in relation to supply, entails that landlords can choose the candidate that he perceives as the best to pay the rent and maintain the dwelling. This context enables the use of selection and discrimination strategies. 
In addition to the gender differences regarding lone parents and ethnicity, we found a large discrepancy in negative treatment according to gender, with regard to financial means. These results made clear that landlords make implicit links between gender and other-more relevant-characteristics (e.g. probability of finding a job in case of 'financial means') when assessing a potential tenant. As long as these implicit links are made to relevant features in the context of renting, discrimination is called statistical instead of taste-based.

Another recent study in Belgium focused on ethnicity as discrimination ground. In 2013, a scientific study, using a paired-testing telephone approach, was carried out in two Flemish cities (Antwerp and Ghent). This study revealed a discrimination rate of 12 percent in the experimental group with no foreign accent, including only male testers (Van der Bracht \& Van de Putte, 2013), This result is thus strongly in line with the rate of 13 per cent we found for men with Moroccan/Turkish names.

The results point out that the level of discrimination that is found depends to a considerable extent on the method that is used. For instance, the discrimination figures turned out lower in the telephone approach than in the email approach for men with a disability or non-labor income. A hypothesis for further research is that landlords find it harder to discriminate on the phone than in a (more anonymous) email.

We also want to stress that getting an appointment does not mean that discrimination will not take place, as it can be encountered in a later stage of the dwelling-seeking process, for instance during the visit or when the landlord makes his choice among the home seekers that expressed their interest in renting the dwelling. These aspects of rental discrimination were clarified in the other parts of the comprehensive Flemish study 'housing diversity barometer' (Interfederal Centre for Equal Opportunities, 2014).

Finally, a policy response is needed to counter the discrimination according to the officially recognized grounds, and selection in case of financial means. As suggested by the Interfederal Centre for Equal Opportunities (2014), these measures may include awareness campaigns, such as the development of a code of ethics for private landlords on the level of professional associations. Moreover, the Centre argues that when the availability of decent, affordable dwellings is assured, discrimination of groups with a weaker socioeconomic profile will decrease. In order to achieve this goal, several structural changes are needed in the Belgian housing market, by both focusing on the role of the private landlords (and the involved risks) and the vulnerability of tenants.

\section{Notes}

1. Two years before the housing diversity barometer, they also commissioned a work diversity barometer in 2012 (Interfederal Centre for Equal Opportunities, 2012) as discrimination also exists in the labor market.

2. In 2012, 86054 Moroccans and 39430 Turks were living in Belgium, which is, respectively, 7 and 3 per cent of the foreign population (Vanduynslager et al., 2013).

\section{Disclosure statement}

No potential conflict of interest were reported by the authors.

\section{References}

Ahmed, A. M., Andersson, L. \& Hammarstedt, M. (2010) Can discrimination in the housing market be reduced by increasing the information about the applicants? Land Economics, 86(1), pp. 79-90. Ahmed, A. M. \& Hammarstedt, M. (2008) Discrimination in the rental housing market: A field experiment on the Internet, Journal of Urban Economics, 64(2), pp. 362-372. 
Ahmed, A. M., Andersson, L. \& Hammarstedt, M. (2008) Are lesbians discriminated against in the rental housing market? Evidence from a correspondence testing experiment, Journal of Housing Economics, 17, pp. 234-238.

Baldini, M. \& Federici, M. (2011) Ethnic discrimination in the Italian rental housing market, Journal of Housing Economics, 20, pp. 1-14.

Bengtsson, R., Iverman, E. \& Hinnerich, B. T. (2012) Gender and ethnic discrimination in the rental housing market, Applied Economics Letters, 19(1), pp. 1-5.

Bosch, M., Carnero, M. A. \& Farré, L. (2010) Information and discrimination in the rental housing market: Evidence from a field experiment, Regional Science and Urban Economics, 40, pp. 11-19.

Carpusor, A. G. \& Loges, W. E. (2006) Rental discrimination and ethnicity in names1, Journal of Applied Social Psychology, 36(4), pp. 934-952.

Choi, S. J., Ondrich, J. \& Yinger, J. (2005) Do rental agents discriminate against minority customers? Evidence from the 2000 housing discrimination study, Journal of Housing Economics, 14, pp. 1-26.

Centre for Equality Rights in Accommodation (CERA) (2009) Measuring Discrimination in Toronto's Rental Housing Market, Toronto, Canada. Available at http://www.equalityrights.org/cera/wpcontent/uploads/2010/04/CERAFinalReport.pdf (accessed 14 January 2013).

Drydakis, N. (2011) Ethnic discrimination in the Greek housing market, Journal of Population Economics, 24(4), pp. 1235-1255.

Galster, G. \& Constantine, P. (1991) Discrimination against female-headed households in rental housing: Theory and exploratory evidence, Review of Social Economy, 49, pp. 76-100.

Hanson, A. \& Hawley, Z. (2011) Do landlords discriminate in the rental housing market? Evidence from an internet field experiment in US cities, Journal of Urban Economics, 70, pp. 99-114.

Heckman, J. J. (1998) Detecting discrimination, Journal of Economic Perspectives, 12(2), pp. 101-116.

Heylen, K. (2013) The distributional impact of housing subsidies in Flanders, International Journal of Housing Policy, 13(1), pp. 37-54.

Heylen, K. (2015) Grote Woononderzoek 2013. Deel 5. De Private Huurmarkt: Vraag-en Aanbodzijde [Large housing research 2013. Part 5. The private rental market: Demand and supply side], Steunpunt Wonen, Leuven, $40 \mathrm{p}$.

Heylen, K. \& Haffner, M. (2013) A ratio or budget benchmark for comparing affordability across countries? Journal of Housing and the Built Environment, 28(3), pp. 547-565.

Interfederal Centre for Equal Opportunities. (2012) Diversity Barometer Work, p. 174, Brussels: Interfederal Equal Opportunities Centre.

Interfederal Centre for Equal Opportunities. (2014) Diversity Barometer Housing, p. 278. Brussels, Interfederal Centre for Equal Opportunities.

Lauster, N. \& Easterbrook, A. (2011) No room for new families? A field experiment measuring rental discrimination against same-sex couples and single parents, Social Problems, 58(3), pp. 389-409.

Riach, P. A. \& Rich, J. (2002) Field experiments of discrimination in the market place, The Economic Journal, 112(483), pp. F480-F518.

Turner, M., Herbig, C., Kaye, D., Fenderson, J. \& Levy, D. (2005) Discrimination Against Persons with Disabilities. Barriers at Every Step (Washington, DC: The Urban Institute-Metropolitan Housing and Communities Policy Center).

Van den Broeck, K. \& Heylen, K. (2014) Discriminatie en Selectie op de Private Huurmarkt in België [Discrimination and selection in the private rental market in Belgium] (KU Leuven: HIVAOnderzoeksinstituut voor Arbeid en Samenleving).

Van der Bracht, K. \& Van de Putte, B. (2013) Het not-in-my-property-syndroom Etnische discriminatie op de huisvestingsmarkt [The not-in-my-property-syndrome. Ethnic discrimination in the housing market]. (Universiteit Gent: Vakgroep Sociologie).

Vanduynslager, L., Wets, J. Noppe, J. \& Doyen, G. (2013) Vlaamse Migratie- en Integratiemonitor 2013, Steunpunt Inburgering en Integratie.

Winters, S. \& Heylen, K. (2014) How housing outcomes vary between the Belgian regions, Journal of Housing and the Built Environment, 29(3), pp. 541-556.

Yinger, J. (1986) Measuring racial discrimination with fair housing audits: Caught in the act, The American Economic Review, 76, pp. 881-893. 